\title{
Asthma and Risk of Lethal Prostate Cancer in the Health Professionals Follow-up Study
}

\author{
Elizabeth A. Platz ${ }^{1,2,3}$, Charles G. Drake ${ }^{2,3,4}$, Kathryn M. Wilson ${ }^{5,6}$, Siobhan Sutcliffe ${ }^{7}$, \\ Stacey A. Kenfield ${ }^{8}$, Lorelei A. Mucci ${ }^{5,6}$, Meir J. Stampfer ${ }^{5,6,9}$, Walter C. Willett ${ }^{5,6,9}$, Carlos \\ A. Camargo Jr. ${ }^{5,9,10}$, and Edward Giovannucci ${ }^{5,6,9}$ \\ ${ }^{1}$ Department of Epidemiology, Johns Hopkins Bloomberg School of Public Health, Baltimore, MD \\ ${ }^{2}$ Sidney Kimmel Comprehensive Cancer Center at Johns Hopkins, Baltimore, MD \\ ${ }^{3}$ Department of Urology and the James Buchanan Brady Urological Institute, Johns Hopkins \\ University School of Medicine, Baltimore, MD \\ ${ }^{4}$ Department of Immunology, Johns Hopkins University School of Medicine, Baltimore, MD \\ ${ }^{5}$ Department of Epidemiology, Harvard School of Public Health, Boston, MA \\ ${ }^{6}$ Channing Division of Network Medicine, Department of Medicine, Brigham and Women's \\ Hospital, Boston, MA \\ ${ }^{7}$ Division of Public Health Sciences and the Siteman Cancer Center, Department of Surgery, \\ Washington University School of Medicine, St. Louis, MO \\ ${ }^{8}$ Department of Urology, University of California San Francisco, San Francisco, CA \\ ${ }^{9}$ Department of Nutrition, Harvard School of Public Health, Boston, MA \\ ${ }^{10}$ Department of Emergency Medicine, Massachusetts General Hospital, Harvard Medical School, \\ Boston, MA
}

\section{Abstract}

Inflammation, and more generally, the immune response are thought to influence the development of prostate cancer. To determine components of the immune response that are potentially contributory, we prospectively evaluated the association of immune-mediated conditions, asthma and hayfever, with lethal prostate cancer risk in the Health Professionals Follow-Up Study. We included 47,880 men ages 40-75 years with no prior cancer diagnosis. On the baseline questionnaire in 1986 the men reported diagnoses of asthma and hayfever and year of onset. On follow-up questionnaires, they reported new asthma and prostate cancer diagnoses. We used Cox proportional hazards regression to estimate relative risks (RR). 9.2\% reported ever having been diagnosed with asthma. $25.3 \%$ reported a hayfever diagnosis at baseline. During 995,176 personyears of follow-up by 2012, we confirmed 798 lethal prostate cancer cases (diagnosed with distant metastases, progressed to distant metastasis, or died of prostate cancer [ $\mathrm{N}=625]$ ). Ever having a diagnosis of asthma was inversely associated with risk of lethal $(\mathrm{RR}=0.71,95 \%$ confidence

Correspondence to: Elizabeth A. Platz, Department of Epidemiology, Room E6132, Johns Hopkins Bloomberg School of Public Health, 615 N. Wolfe Street, Baltimore, MD 21205 USA. Tel: [+1-410-614-9674], Fax: [+1-410-614-2632], eplatz1@jhu.edu.. 
interval [CI] 0.51-1.00) and fatal ( $R R=0.64,95 \% \mathrm{CI} 0.42-0.96)$ disease. Hayfever with onset in the distant past was possibly weakly positively associated with risk of lethal (RR=1.10, 95\% CI 0.92-1.33) and fatal (RR=1.12, 95\% CI 0.91-1.37) disease. Men who were ever diagnosed with asthma were less likely to develop lethal and fatal prostate cancer. Our findings may lead to testable hypotheses about specific immune profiles in the etiology of lethal prostate cancer.

\section{Keywords}

Asthma; hayfever; prostate cancer; risk; men

\section{Introduction}

Emerging evidence suggests that inflammation, ${ }^{1}$ and more generally, the immune response contribute to prostate cancer etiology. ${ }^{2}$ One strategy for determining the components of the immune response potentially involved in the development of this cancer is to evaluate the association between conditions exhibiting particular immune profiles and risk of total or lethal prostate cancer. Two such immune-mediated conditions are asthma and allergy, including hayfever.

Asthma is a condition characterized by intermittent airway obstruction, hyper-responsivity of bronchial smooth muscle, and permanent changes to tissue lining the airways including fibrosis. ${ }^{3}$ Allergic asthma is mediated by $\mathrm{T}_{\mathrm{H}} 2$ (i.e., IL-4, IL-5, IL-10, IL-13) cytokines, and eosinophils (a type of granulocyte) are often present. ${ }^{4,5}$ Asthma with a preponderance of neutrophils rather than eosinophils is also recognized based on array of granulocytes in sputum. ${ }^{6,7}$ Hayfever broadly encompasses seasonal allergy to pollen plus general allergic rhinitis, atopic conditions that are mediated by IgE responses to antigens. ${ }^{3}$ Hayfever symptoms are produced by actions of histamine released from IgE-bound mast cells when an allergen binds to the antigen-binding site on $\operatorname{IgE} .{ }^{8}$ Both asthma and hayfever/allergic rhinitis are generally considered to be associated with a $\mathrm{T}_{\mathrm{H}} 2$-mediated immune response.

Whether asthma and hayfever are associated with prostate cancer risk has been evaluated in a small number of studies. In a meta-analysis of studies published through 2008, asthma $(\mathrm{N}=8$, summary $\mathrm{RR}=0.93 ; 95 \% \mathrm{CI} 0.76-1.15)$, hayfever $(\mathrm{N}=5$, summary $\mathrm{RR}=0.96 ; 95 \% \mathrm{CI}$ 0.87-1.05), and allergy ( $\mathrm{N}=4$, summary $\mathrm{RR}=1.01,95 \% \mathrm{CI} 0.87-1.17)$ were not associated with overall prostate cancer risk. ${ }^{9}$ For asthma, included studies reported inverse, null, and positive associations. ${ }^{9}$ Excluded studies and subsequent studies have also found a range of associations between asthma and prostate cancer risk: positive associations (cohort, $\mathrm{RR}=1.25,95 \% \mathrm{CI} 1.05-1.49^{10}$; registry linkage, $\left.\mathrm{SIR}=1.36,95 \% \mathrm{CI} 1.29,1.44^{11}\right)$, although not for aggressive disease ( $R R=1.08,95 \%$ CI $\left.0.76-1.54^{10}\right)$; a non-significant inverse association (population-based case-control study, $\mathrm{OR}=0.70,95 \% \mathrm{CI} 0.4-1.3^{12}$ ); and no association ( 2 population-based case-control studies, OR=0.87, 95\% CI 0.61-1.2313; $\left.\mathrm{OR}=1.11,95 \% \mathrm{CI} 0.89-1.40^{14}\right)$. Only two of the studies on asthma specifically investigated aggressive prostate cancer. ${ }^{10,14,15}$ While many of the other studies were conducted in the pre-PSA era in the US or in countries in which prostate cancer screening was not routinely done, the association for asthma with lethal prostate cancer was not specifically investigated. 
Given the inconsistent findings and lack of focus on the most clinically relevant prostate cancer phenotype, we evaluated the association of asthma and hayfever with risk of lethal prostate cancer and overall disease, in a prospective cohort study of 6,294 prostate cancer cases, of which 798 were lethal, ascertained in 995,176 person-years of follow-up.

\section{Materials and Methods}

\section{Study population}

The study population was participants in the Health Professionals Follow-up Study, an ongoing prospective cohort of 51,529 men aged 40-75 years old at enrollment in 1986. 91\% of the participants are white. Biennially, the men complete mailed questionnaires on demographics, medical history, and lifestyle factors, and every four years complete semiquantitative food frequency questionnaires. Deaths are reported by family members or the postal system or are identified through the National Death Index, which is estimated to have a sensitivity $>98 \% .{ }^{16}$ The response to biennial questionnaires among men eligible to receive them is $94 \%$. We excluded men with a cancer diagnosis (except non-melanoma skin cancer) before $1986(4.0 \%, \mathrm{~N}=2,074)$, who returned an incomplete or invalid diet questionnaire in $1986(3.1 \%, \mathrm{~N}=1,584)$, men who withdrew or were otherwise ineligible $(0.1 \%, \mathrm{~N}=55)$ leaving 47,880 men. The Human Subjects Committee of the Harvard School of Public Health approved the conduct of the Health Professionals Follow-up Study.

\section{Assessment of asthma and hayfever}

At baseline in 1986 the men were asked to report whether they had ever been diagnosed with asthma, or with "hayfever, other allergy", and year of onset (before 1955, 1955-1964, 1965-1974, 1975-1979, 1980-1986). New asthma diagnoses were solicited on the 1992, and 1996 through 2010 questionnaires (new hayfever diagnoses were not requested). Starting in 1988 and biennially onward, we asked them to report whether they were currently taking oral steroids, and in 1988, 1990, and 1992 whether they were currently taking beta-agonists; patients with asthma are sometimes prescribed these medications for symptom treatment.

\section{Ascertainment and classification of prostate cancer cases}

For each man who reported a prostate cancer diagnosis on a follow-up questionnaire or when prostate cancer was mentioned on the death certificate, we sought medical and pathology reports pertaining to the diagnosis. Medical records and pathology reports were obtained for $90 \%$. An investigator blinded to exposure reviewed the records to confirm the diagnosis and to abstract clinical data, including treatment, PSA at diagnosis, stage, and Gleason sum. Because reporting of prostate cancer was found to be accurate, we included the remaining $10 \%$ of cases that were based solely on self-report or death certificate. We excluded T1a cases because these are generally indolent and susceptible to detection bias due to differential rates of surgery for benign prostatic hyperplasia. From enrollment in 1986 through January 31, 2012, 6,294 cases of incident prostate cancer were confirmed during 995,176 person-years of follow up. Of these, 798 were lethal (distant metastatic at diagnosis [M1] or during follow-up, or fatal [underlying cause of death was prostate cancer]), and of these, 625 were fatal. In this work, we focused on lethal more so than total prostate cancer because lethal disease is the most relevant clinical outcome and it is less prone to detection 
bias due to PSA-based prostate cancer screening. Further, prostate cancer etiology appears to be heterogeneous and most risk factors are only associated with lethal or fatal disease. ${ }^{17}$

\section{Statistical analysis}

We calculated age-standardized means and proportions for baseline demographic and other factors by baseline history of asthma, and hayfever and other allergy (called hayfever throughout). We used Cox proportional hazards regression to calculate age- and multivariable-adjusted hazard ratios (relative risks; RR) and 95\% confidence intervals (CI) of total, lethal, and fatal prostate cancer for history of asthma at baseline (modeled as a fixed exposure), and ever having a diagnosis of asthma (modeled as an updated exposure during follow-up). We also calculated RRs for history of hayfever at baseline. We further evaluated associations for histories of asthma or hayfever at baseline by whether onset was in the distant past ( $>30$ years before baseline, which equates to childhood [minimum of age 9] to early mid-adulthood [maximum of age 44]) or in the more recent past relative to baseline. In the multivariable analysis, we adjusted for prostate cancer risk and protective factors previously identified in this cohort: ${ }^{17}$ age, race (African-American, Asian, other ancestry, white), first degree family history of prostate cancer, height (inches), body mass index (BMI, $\mathrm{kg} / \mathrm{m}^{2}$, updated), BMI at age $21\left(\mathrm{~kg} / \mathrm{m}^{2}\right)$, vigorous physical activity (MET-hours/ week, updated), diabetes (updated), cigarette smoking in the past 10 years (pack-years, updated). Results were similar after adjustment for diet and nutrient intake (energy, bacon, tomato sauce, fish, alpha-linolenic acid, calcium, supplemental vitamin E) or medication use (aspirin, ${ }^{18}$ cholesterol-lowering drugs, ${ }^{19}$ digoxin $^{20}$ ). Thus, final multivariable models are not adjusted for diet, nutrients, or use of these medications.

In a subanalysis, we evaluated the association for ever having a diagnosis of asthma in men not using oral steroid medications because these medications change the immune profile (e.g., suppress eosinophils, but not neutrophils). ${ }^{21}$ Because chronic obstructive pulmonary disease (COPD) and asthma may have overlapping symptomatology in older adults, we repeated the main analysis for asthma excluding men with a confirmed diagnosis of COPD based on a 1998 supplementary questionnaire sent to men reporting a diagnosis of chronic bronchitis or emphysema before 1996 on the baseline or follow-up questionnaires; ${ }^{22}$ for this analysis, we began follow-up in 1998. Because cancer screening utilization could differ between men with and without conditions that affect frequency of medical contact, such as asthma and allergy, in a subanalysis we started follow-up in 1994, the first year we asked the men about PSA screening, and only included time at risk during which a screening PSA test was done.

We ran stratified models to assess whether the associations of ever having a diagnosis of asthma with prostate cancer varied by age at prostate cancer diagnosis $(<60, \geq 60$ years old $)$ and family history of prostate cancer. We also stratified by BMI $\left(<25,225 \mathrm{~kg} / \mathrm{m}^{2}\right)$, ever cigarette smoking (no, yes), and cigarette smoking in the past 10 years (no, yes). We performed these latter stratifications because asthma may have a different etiology, including immune profile in obese and non-obese individuals, ${ }^{23}$ and smoking-associated asthma tends to be less eosinophilic, and possibly more neutrophilic than asthma not associated with smoking. ${ }^{24}$ In this cohort, current smoking and quitting within the past 10 
years are associated with fatal prostate cancer, but not quitting $>10$ years ago. ${ }^{17} \mathrm{We}$ ran these same stratified analyses for history of hayfever and its onset. To test for multiplicative interaction, we entered into the models the main effects terms along with a cross-product term(s) for ever having a diagnosis of asthma, history of hayfever, or hayfever onset, and each stratification factor, the coefficients for which were evaluated by the Wald test. Analyses were performed using SAS release 9.3 (SAS Institute, Cary, NC). All tests were 2sided.

\section{Results}

\section{Asthma}

Of the 47,880 men, 2,516 (5.3\%) had a history of asthma at baseline. Men with and without a history of asthma were similar on baseline demographic, dietary, and lifestyle characteristics. However, men with a history of asthma were more likely to have a history of hayfever and to regularly use oral steroids and theophylline than men without a history of asthma (Table 1). $69.0 \%$ of the men with a history of asthma at baseline were diagnosed $>30$ years ago. Of the prostate cancer cases with known TNM stage, $81.4 \%$ had T1-T2 (excluding T1a), N0, M0 disease. Of the cases with known grade, $44.5 \%$ had Gleason sum $\geq 7$ or higher $(12.6 \%$ had $\geq 8)$ disease. Of the lethal cases with known TNM stage, $40.9 \%$ had $\mathrm{N} 1$ and/or M1 disease at the time of diagnosis. Of the lethal cases with known grade, $72.0 \%$ had Gleason sum $\geq 7$ or higher $(37.8 \%$ had $\geq 8)$ disease.

Associations were similar after age and multivariable adjustment (Table 2), thus, ageadjusted RRs are reported throughout. A history of asthma at baseline was modestly inversely associated with total prostate cancer risk, and even more strongly inversely associated with lethal (Table 2 ) and especially fatal ( $R R=0.56,95 \%$ CI $0.34-0.91)$ prostate cancer. The associations for lethal and fatal prostate cancer were similar in men who had both asthma and hayfever and in men with asthma only when compared to men with neither (data not shown). Men with asthma onset in the more recent past relative to baseline had an even lower risk of total and lethal prostate cancer than men with an onset in the distant past (Table 3).

Of the men without a history of asthma at baseline, 1,906 (4.2\%) were diagnosed with the condition during follow-up. As for a history of asthma at baseline, ever having a diagnosis of asthma (i.e., updating a baseline history of asthma during follow-up) was inversely associated with total, lethal, (Table 4 ) and fatal ( $\mathrm{RR}=0.64,95 \% \mathrm{CI} 0.42-0.96$ ) prostate cancer. Associations remained inverse after excluding oral steroid users (data not shown). After excluding person-time at risk following a confirmed COPD diagnosis ( $\mathrm{N}=361$ diagnosed prior to 1996; starting follow-up in 1998), the association for ever having had a history of asthma remained inverse for total ( $\mathrm{RR}=0.90,95 \%$ CI 0.80-1.02), lethal ( $\mathrm{RR}=0.57$, 95\% CI 0.31-1.04), and fatal ( $\mathrm{RR}=0.4495 \%$ CI 0.19-0.99) prostate cancer. Including periods during which the men had had a screening PSA test (starting follow-up in 1994), the association between ever having a diagnosis of asthma and prostate cancer remained inverse (total: $\mathrm{N}$ [cases] $=3,123, \mathrm{RR}=0.86,95 \% \mathrm{CI} 0.76-0.99$, lethal: $\mathrm{N}=228, \mathrm{RR}=0.33,95 \% \mathrm{CI}$ 0.15-0.74, fatal: $\mathrm{N}=162, \mathrm{RR}=0.24,95 \%$ CI $0.08-0.74)$. 
The inverse association for ever having a diagnosis of asthma was present for men diagnosed with prostate cancer younger than age 60 years old, but not older ages, (pinteraction $=0.047$; Table 4 ). This pattern was also observed for lethal prostate cancer, albeit based on few cases. The associations for total and lethal prostate cancer did not differ by family history of prostate cancer or BMI (all p-interaction>0.6; Table 4). In never smokers, the association was attenuated for total prostate cancer $(\mathrm{RR}=0.95,95 \% \mathrm{CI} 0.81-1.11)$, but remained inverse appearing for lethal disease ( $R R=0.79,95 \% 0.47-1.33)$. In ever smokers, the association was inverse for total $(\mathrm{RR}=0.90,95 \% \mathrm{CI} 0.79-1.03$, p-interaction $=0.60)$ and for lethal $(R R=0.67,95 \% 0.43-1.05$, $p$-interaction $=0.61)$ prostate cancer. The association for ever having had a diagnosis of asthma in men who never smoked or who quit $>10$ years ago was almost identical to the overall RR for both total and lethal prostate cancer, while the association was null (total prostate cancer, $\mathrm{p}$-interaction $=0.68$ ) or attenuated (lethal disease, $\mathrm{p}$-interaction $=0.91$ ) in men who were current smokers or who quit within the past 10 years (Table 4).

\section{Hayfever}

Of the 47,880 men, 12,114 (25.3\%) had a history of hayfever at baseline. Men with and without hayfever did not differ in their characteristics with the exception of history of asthma at baseline (Table 1). Age- and multivariable-adjusted RRs were similar (Table 2); age-adjusted estimates are presented throughout. Men with hayfever had a very slight increased risk of total prostate cancer (Table 2). Compared with men without hayfever or asthma, the HR of total prostate cancer was similar when restricting the hayfever group to men without asthma (data not shown). The association for hayfever was stronger if onset was in the distant past (Table 3); this same pattern was present for lethal (Table 3) and possibly fatal ( $\mathrm{RR}=1.12,95 \% \mathrm{CI} 0.91-1.37)$ disease.

The positive association between a history of hayfever and total prostate cancer was stronger for men who were younger ( $\mathrm{RR}=1.25,95 \% \mathrm{CI} 1.07-1.47)$ than older $(\mathrm{RR}=1.05,95 \% \mathrm{CI}$ 0.99-1.11; p-interaction=0.04) at prostate cancer diagnosis, especially for an onset in the distant past (Table 5). In contrast, for lethal disease, the positive association for hayfever appeared to be present in men who were older ( $R R=1.09,95 \%$ CI 0.92-1.30), but not younger ( $\mathrm{RR}=0.75,95 \% \mathrm{CI} 0.43-1.31$ ) at prostate cancer diagnosis (both p-interaction $>0.20$ ), including for an onset in the distant past (Table 5). Patterns for fatal prostate cancer

were similar to lethal disease (data not shown). The association of hayfever with total, lethal, and fatal prostate cancer did not differ by family history or BMI (all p-interaction $>0.30$ ). The association of hayfever and prostate cancer was stronger in men who had smoked within the past 10 years than in never smokers and those who quit $>10$ years ago (pinteraction $=0.04$ ), especially if hayfever onset was in the distant past (Table 5). This pattern was also present for lethal (Table 5) and fatal disease (data not shown).

Including only periods during which the men had a PSA test (starting follow-up in 1994), hayfever, including onset in the distant past, was not associated with total prostate cancer (data not shown). However, even among men who were screened, the association for hayfever $(\mathrm{RR}=1.32,95 \% \mathrm{CI} 0.99-1.76)$ in men who smoked within the past 10 years 
remained positive, as did the association for hayfever onset in the distant past in men who were younger at prostate cancer diagnosis ( $\mathrm{RR}=1.22,95 \% \mathrm{CI} 0.90-1.64)$.

\section{Discussion}

In this large prospective cohort study, we observed that men who ever had a diagnosis of asthma, especially if onset was in the more recent past, had a lower risk of lethal and fatal prostate cancer as well as total prostate cancer. In contrast, men with a history of hayfever had a slightly higher risk of total prostate cancer, especially if hayfever onset was in the distant past and in men who were current smokers or recent quitters. These same patterns of association for hayfever were generally present for lethal and fatal prostate cancer.

The small number of prior studies investigating asthma and prostate cancer have not produced consistent results; inverse, ${ }^{12,25-27}$ null, ${ }^{13-15,28,29}$ and positive ${ }^{10,11,30,31}$ associations have been reported. A Japanese study that was excluded from the meta-analysis because of small sample size, ${ }^{9}$ reported a positive association for treated asthma. ${ }^{32}$ While most prior studies did not comment on the association for aggressive disease, the majority were conducted in the pre-PSA era in the US ${ }^{25,28}$ or in countries in which prostate cancer screening was not routinely done at least in the past, ${ }^{11-13,26,27,29-31}$ and thus the prostate cancer cases would be more likely to be detected at a clinical stage. The other three studies specifically investigated aggressive disease. ${ }^{10,14,15}$ Severi et al. evaluated the association for self-reported physician diagnosed asthma at baseline in the Melbourne Collaborative Cohort Study (Australia). ${ }^{10}$ No association was observed for aggressive disease, which they defined as Gleason sum $\geq 7$, poorly differentiated, $\mathrm{T} 4, \mathrm{~N}+, \mathrm{M}+$, or fatal, despite an overall association in the positive direction. Turner et al. investigated the association between selfreported physician-diagnosed asthma and death from prostate cancer in the Cancer Prevention Study II (US); no association was observed. ${ }^{15}$ In a population based-case control study, Weiss et al. reported no association for aggressive disease, which they defined as a Gleason $>7$ or 7 with a primary pattern of $4 .{ }^{14}$ Using the same asthma definition, our findings for lethal prostate cancer differ from the two prospective studies; ${ }^{10,15}$ explanations are not evident.

We noted that a more recent asthma onset relative to baseline (well into adulthood) was more strongly inversely associated with prostate cancer, including lethal disease, than a more distant onset (childhood through early mid-adulthood). Asthma onset in older adulthood as opposed to at a younger age may correspond to a greater likelihood of asthma or its immunologic pathology being present during the etiologically relevant time (e.g., less misclassification). Alternatively, an older age at asthma onset may have a different underlying immunologic pathology than at a younger age. In contrast to our findings, Severi et al. reported an overall increased prostate cancer risk in men with asthma and no difference in the association by age at asthma onset ${ }^{10}$, and Weiss et al. reported a null association and no patterns emerged for age at asthma onset or asthma duration. ${ }^{14} \mathrm{We}$ also noted that the asthma association was more strongly inverse for prostate cancer diagnosed at a younger age, which could indicate an underlying predisposition. ${ }^{33}$ However, we did not observe a stronger inverse association for men with a family history of prostate cancer. Thus, the observation of a stronger inverse association between asthma and prostate cancer diagnosed 
at a younger age also may be reflective of less misclassification of the etiologically relevant window.

A meta-analysis reported no association for hayfever (summary RR=0.96; 95\% CI $0.87-1.05$ ) or any allergy (summary $\mathrm{RR}=1.01,95 \%$ CI $0.87-1.17$ ) and prostate cancer risk. ${ }^{9}$ An additional country-based registry linkage study reported a positive association ( $\left.\mathrm{SIR}=1.18,95 \% \mathrm{CI} 1.06-1.30^{34}\right)$ and a population-based case-control reported an inverse association ( $\mathrm{OR}=0.79,95 \% \mathrm{CI} 0.61-1.00)$ between allergy and prostate cancer risk. ${ }^{13}$ In our study, we observed a weak, but statistically significant, positive association between hayfever and total prostate cancer. The association was stronger for an onset in the distant past, for men with a younger age at prostate cancer diagnosis, and for men who were current smokers or recent quitters. The latter two associations were not explained by differential uptake of PSA screening. These patterns of association were also present for lethal and fatal prostate cancer. We were able to conduct extensive subgroup analyses because of the very large number of both hayfever and prostate cancer cases in this cohort. Whether the other studies would have observed similar associations within these subgroups is unknown.

We evaluated asthma as a marker for the tendency for skewing of helper $\mathrm{T}$ cell $\left(\mathrm{CD} 4^{+}\right)$ differentiation toward a $\mathrm{T}_{\mathrm{H}} 2$ response; this skewing is partially genetically controlled. ${ }^{35} \mathrm{~A}$ $\mathrm{T}_{\mathrm{H}} 2$ skewed $\mathrm{T}$ cell response results in a number of clinico-pathological immune system alterations, which may have opposing effects on cancer development. On one hand, $\mathrm{T}_{\mathrm{H}} 2$ responses have consistently been associated with chronic inflammation and accompanying local tissue infiltration. ${ }^{36,37}$ A relationship between chronic inflammation and tumorigenesis has been established for some epithelial malignancies, including colon cancer, gastric cancer, and liver cancer. ${ }^{37} \mathrm{~A}$ similar association has been proposed for prostate cancer, including for more aggressive disease, ${ }^{1,2}$ but is not yet firmly established. ${ }^{1,2}$ If chronic prostatic inflammation mediated by $\mathrm{T}_{\mathrm{H}} 2$ skewing at the tissue level were important in the pathogenesis of prostate cancer, we would have expected the opposite result to what we observed - that asthmatics would have had a higher incidence of more aggressive prostate cancer.

On the other hand, $\mathrm{T}_{\mathrm{H}} 2$ skewed immune responses are associated with increased IgE levels and increased numbers of circulating eosinophils. Asthmatics often have elevated systemic eosinophil and IgE levels. ${ }^{38} \mathrm{~A}$ large body of data points to an important role for eosinophils in an anti-tumor immune response. Initial studies by Coffman et al. showed that $\mathrm{T}_{\mathrm{H}} 2$ skewing mediated by administration of IL-4 resulted in a notable anti-tumor immune response that was dependent on eosinophils. ${ }^{39}$ For prostate cancer, an in vitro study showed that eosinophils could directly lyse prostate cancer cells. ${ }^{40}$ Our asthma findings are compatible with this mechanism. In contrast, In a nested case-control study, Wang et al. observed that IgE seropositivity for common inhaled allergens was positively associated with prostate cancer, ${ }^{29}$ which argues against this mechanism for asthma, although it may support our finding of a positive association between hayfever and prostate cancer.

As shown in Figure 1 (modified from Tato and O'Shea ${ }^{41}$ ), CD4+ helper T cells can differentiate into several major phenotypes based on the microenvironment present during initial antigen encounter. ${ }^{41}$ In particular, an environment with abundant IL-4 promotes a 
$\mathrm{T}_{\mathrm{H}} 2$ response. $\mathrm{CD}^{+}$helper $\mathrm{T}$ cell skewing involves feedback loops, such that differentiation down one pathway tends to inhibit differentiation down another. In this regard, it is notable that $\mathrm{CD}^{+}$helper $\mathrm{T}$ cells skewed toward a $\mathrm{T}_{\mathrm{H}} 17$ phenotype (under the influence of IL- 6 and TGF- $\beta$ ) have been associated with chronic inflammation and cancer in both murine and human studies. ${ }^{42}$ Indeed, we ${ }^{43}$ and others have observed $\mathrm{T}_{\mathrm{H}} 17 \mathrm{~T}$ cells in the human prostate. Thus, another possible explanation for the inverse association between an asthma diagnosis and lethal prostate cancer might be that patients with asthma have a genetic and/or environmental propensity for $\mathrm{CD}^{+}{ }^{+}$helper $\mathrm{T}$ cell response skewed away from a $\mathrm{T}_{\mathrm{H}} 17$ response.

Finally, the associations observed here could also involve a set of $\mathrm{CD} 4^{+}$helper $\mathrm{T}$ cells known as regulatory $\mathrm{T}$ cells (Treg) ${ }^{44}$ These cells, which either arise naturally in the thymus or are induced peripherally under the influence of TGF- $\beta$, serve to down regulate an immune reaction. An accumulating body of data suggests that Tregs are deficient in either number or in function in patients with asthma. ${ }^{45}$ Increased Treg activity has been proposed to limit the host response to tumor. ${ }^{46,47}$ Thus, an additional hypothesis to explain the inverse association between asthma and lethal prostate cancer that we observed might be that the relative paucity of Treg activity reported in asthmatics leads to improved tumor immunosurveillance. ${ }^{48}$

Our study has a number of strengths that lend credence to the findings, and has some areas for discussion. The analysis was prospective and included substantially more prostate cancer cases than in any other studies reporting on these conditions in relation to prostate cancer. We had sufficient sample size to be able to focus on the most clinically relevant prostate cancer outcome, lethal disease. These analyses used self-reported diagnosis of asthma and hayfever. Because the men were highly trained health professionals, the self-reporting of diseases is generally accurate. Moreover, because the men reported on their asthma and hayfever diagnoses prior to their prostate cancer diagnosis, any reporting inaccuracy could not explain the inverse (asthma) and positive (hayfever) associations observed (e.g., the expected influence of this non-differential bias is to underestimate the strength of these associations). We performed a sensitivity analysis to address possible misclassification of COPD as asthma. The inverse association between asthma and lethal and fatal prostate cancer remained, suggesting that our findings are not explained by another pulmonary condition. We asked the men to report on "hayfever, other allergy". We do not know what proportion of affirmative responses was for hayfever, what they other types of allergies were, or whether men with other allergies would have responded affirmatively to the question. Nevertheless, after excluding from the hayfever group men who also had asthma, which would leave the hayfever only group less enriched with men with seasonal allergies, the results remained the same, suggesting that most of the men actually did have hayfever rather than other allergies, or prostate cancer risk is the same for both hayfever and for other allergies.

We did not directly measure biomarkers indicative of the immune profile of the men with asthma (e.g., eosinophilic versus neutrophilic) or hayfever (e.g., types of allergens).

However, in subanalyses we categorized men based on profiles that might provide etiologic insight, such as the combination of asthma and hayfever, the timing of asthma onset, 
smoking, and BMI. We considered confounding by known and suspected risk factors for total and lethal prostate cancer in this cohort, including smoking. ${ }^{17}$ We were able to show that the associations we observed were not fully due to the differential screening for PSA by history of asthma or hayfever. The asthma findings were not explained by oral steroids treatment. We do not have information on use of inhaled asthma medications for the majority of the men with asthma. While inhaled steroids could have suppressed any of the responses $\left(\mathrm{T}_{\mathrm{H}} 1, \mathrm{~T}_{\mathrm{H}} 2\right.$ or $\left.\mathrm{T}_{\mathrm{H}} 17\right)$, it is unlikely that they would do so in the prostate because these drugs are poorly absorbed systemically. ${ }^{49}$

In summary, in this large prospective cohort, men who ever had a diagnosis of asthma were less likely to develop prostate cancer, especially lethal and fatal disease. Men with hayfever onset in the distant past were slightly more likely to be diagnosed with total and possibly lethal and fatal prostate cancer. While at this time we do not have an explanation for the difference in the direction of the associations for asthma and hayfever with prostate cancer, our findings may lead to testable hypotheses about specific immune profiles in the etiology of lethal prostate cancer and the disease overall.

\section{Acknowledgments}

We would like to thank the participants and staff of the Health Professionals Follow-up Study, for their valuable contributions as well as the following state cancer registries for their help: AL, AZ, AR, CA, CO, CT, DE, FL, GA, ID, IL, IN, IA, KY, LA, ME, MD, MA, MI, NE, NH, NJ, NY, NC, ND, OH, OK, OR, PA, RI, SC, TN, TX, VA, WA, WY. In addition, this study was approved by the Connecticut Department of Public Health (DPH) Human Investigations Committee. Certain data used in this publication were obtained from the DPH. The authors assume full responsibility for analyses and interpretation of these data.

Grant sponsor: This study was supported by the National Cancer Institute (P01 CA55075 and R01 CA133891 [Harvard], and P30 CA006973 and P50 CA58236 [Johns Hopkins]) and the National Heart, Lung, and Blood Institute (R01 HL35464 [Harvard]). None of the sponsors played a role in the study design, collection, analysis, and interpretation of the data, in the writing of this report, or in the decision to submit the paper for publication. The content of this work is solely the responsibility of the authors and does not necessarily represent the official views of the NIH.

\section{References}

1. Gurel B, Lucia MS, Thompson IM Jr, Goodman PJ, Tangen CM, Kristal AR, Parnes HL, Hoque A, Lippman SM, Sutcliffe S, Peskoe SB, Drake CG, et al. Chronic inflammation in benign prostate tissue is associated with high-grade prostate cancer in the placebo arm of the prostate cancer prevention trial. Cancer Epidemiol Biomarkers Prev. 2014; 23:847-56. [PubMed: 24748218]

2. De Marzo AM, Platz EA, Sutcliffe S, Xu J, Gronberg H, Drake CG, Nakai Y, Isaacs WB, Nelson WG. Inflammation in prostate carcinogenesis. Nat Rev Cancer. 2007; 7:256-69. [PubMed: 17384581]

3. National Asthma Education and Prevention Program NH, Lung, and Blood Institute; National Institutes of Health; US Department of Health and Human Services. Expert Panel Report 3: Guidelines for the Diagnosis and Management of Asthma. 2007

4. Walsh ER, August A. Eosinophils and allergic airway disease: there is more to the story. Trends Immunol. 2010; 31:39-44. [PubMed: 19926338]

5. Walford HH, Doherty TA. Diagnosis and management of eosinophilic asthma: a US perspective. J Asthma Allergy. 2014; 7:53-65. [PubMed: 24748808]

6. Douwes J, Gibson P, Pekkanen J, Pearce N. Non-eosinophilic asthma: importance and possible mechanisms. Thorax. 2002; 57:643-8. [PubMed: 12096210]

7. Simpson JL, Scott R, Boyle MJ, Gibson PG. Inflammatory subtypes in asthma: assessment and identification using induced sputum. Respirology. 2006; 11:54-61. [PubMed: 16423202] 
8. Osguthorpe JD. Pathophysiology of and potential new therapies for allergic rhinitis. Int Forum Allergy Rhinol. 2013; 3:384-92. [PubMed: 23193028]

9. Vojtechova P, Martin RM. The association of atopic diseases with breast, prostate, and colorectal cancers: a meta-analysis. Cancer Causes Control. 2009; 20:1091-105. [PubMed: 19340595]

10. Severi G, Baglietto L, Muller DC, English DR, Jenkins MA, Abramson MJ, Douglass JA, Hopper JL, Giles GG. Asthma, asthma medications, and prostate cancer risk. Cancer Epidemiol Biomarkers Prev. 2010; 19:2318-24. [PubMed: 20671137]

11. Ji J, Shu X, Li X, Sundquist K, Sundquist J, Hemminki K. Cancer risk in hospitalised asthma patients. Br J Cancer. 2009; 100:829-33. [PubMed: 19174822]

12. El-Zein M, Parent ME, Ka K, Siemiatycki J, St-Pierre Y, Rousseau MC. History of asthma or eczema and cancer risk among men: a population-based case-control study in Montreal, Quebec, Canada. Ann Allergy Asthma Immunol. 2010; 104:378-84. [PubMed: 20486327]

13. Lightfoot N, Conlon M, Kreiger N, Sass-Kortsak A, Purdham J, Darlington G. Medical history, sexual, and maturational factors and prostate cancer risk. Ann Epidemiol. 2004; 14:655-62. [PubMed: 15380796]

14. Weiss D, El-Zein M, Rousseau MC, Richard H, Karakiewicz PI, Parent ME. Asthma, allergy and the risk of prostate cancer: Results from the Montreal PROtEuS study. Cancer Epidemiol. 2014; 38:695-9. [PubMed: 25453783]

15. Turner MC, Chen Y, Krewski D, Ghadirian P, Thun MJ, Calle EE. Cancer mortality among US men and women with asthma and hay fever. Am J Epidemiol. 2005; 162:212-21. [PubMed: 15987724]

16. Stampfer MJ, Willett WC, Speizer FE, Dysert DC, Lipnick R, Rosner B, Hennekens CH. Test of the National Death Index. Am J Epidemiol. 1984; 119:837-9. [PubMed: 6720679]

17. Giovannucci E, Liu Y, Platz EA, Stampfer MJ, Willett WC. Risk factors for prostate cancer incidence and progression in the Health Professionals Follow-up Study. Int J Cancer. 2007; 121:1571-8. [PubMed: 17450530]

18. Leitzmann MF, Stampfer MJ, Ma J, Chan JM, Colditz GA, Willett WC, Giovannucci E. Aspirin use in relation to risk of prostate cancer. Cancer Epidemiol Biomarkers Prev. 2002; 11:1108-11. [PubMed: 12376516]

19. Platz EA, Leitzmann MF, Visvanathan K, Rimm EB, Stampfer MJ, Willett WC, Giovannucci E. Statin drugs and risk of advanced prostate cancer. J Natl Cancer Inst. 2006; 98:1819-25. [PubMed: 17179483]

20. Platz EA, Yegnasubramanian S, Liu JO, Chong CR, Shim JS, Kenfield SA, Stampfer MJ, Willett WC, Giovannucci E, Nelson WG. A novel two-stage, transdisciplinary study identifies digoxin as a possible drug for prostate cancer treatment. Cancer Discov. 2011; 1:68-77. [PubMed: 22140654]

21. Barnes PJ, Adcock IM. How do corticosteroids work in asthma? Ann Intern Med. 2003; 139:35970. [PubMed: 12965945]

22. Varraso R, Fung TT, Hu FB, Willett W, Camargo CA. Prospective study of dietary patterns and chronic obstructive pulmonary disease among US men. Thorax. 2007; 62:786-91. [PubMed: 17504819]

23. Kim SH, Sutherland ER, Gelfand EW. Is There a Link Between Obesity and Asthma? Allergy Asthma Immunol Res. 2014; 6:189-95. [PubMed: 24843792]

24. Fattahi F, Hylkema MN, Melgert BN, Timens W, Postma DS, ten Hacken NH. Smoking and nonsmoking asthma: differences in clinical outcome and pathogenesis. Expert Rev Respir Med. 2011; 5:93-105. [PubMed: 21348590]

25. Vena JE, Bona JR, Byers TE, Middleton E Jr. Swanson MK, Graham S. Allergy-related diseases and cancer: an inverse association. Am J Epidemiol. 1985; 122:66-74. [PubMed: 4014202]

26. Kallen B, Gunnarskog J, Conradson TB. Cancer risk in asthmatic subjects selected from hospital discharge registry. Eur Respir J. 1993; 6:694-7. [PubMed: 8519380]

27. Gonzalez-Perez A, Fernandez-Vidaurre C, Rueda A, Rivero E, Garcia Rodriguez LA. Cancer incidence in a general population of asthma patients. Pharmacoepidemiol Drug Saf. 2006; 15:1318. [PubMed: 16287212]

28. Mills PK, Beeson WL, Fraser GE, Phillips RL. Allergy and cancer: organ site-specific results from the Adventist Health Study. Am J Epidemiol. 1992; 136:287-95. [PubMed: 1415150] 
29. Wang H, Rothenbacher D, Low M, Stegmaier C, Brenner H, Diepgen TL. Atopic diseases, immunoglobulin $\mathrm{E}$ and risk of cancer of the prostate, breast, lung and colorectum. Int J Cancer. 2006; 119:695-701. [PubMed: 16506215]

30. Vesterinen E, Pukkala E, Timonen T, Aromaa A. Cancer incidence among 78,000 asthmatic patients. Int J Epidemiol. 1993; 22:976-82. [PubMed: 8144310]

31. Talbot-Smith A, Fritschi L, Divitini ML, Mallon DF, Knuiman MW. Allergy, atopy, and cancer: a prospective study of the 1981 Busselton cohort. Am J Epidemiol. 2003; 157:606-12. [PubMed: 12672680]

32. Ohrui T, Yamaya M, Sato T, Matsui T, Sasaki H, Namima T. Risk of prostate cancer in older Japanese asthmatics. J Am Geriatr Soc. 2002; 50:202. [PubMed: 12028273]

33. Grönberg H, Damber L, Damber JE. Familial prostate cancer in Sweden. A nationwide register cohort study. Cancer. 1996; 77:138-43. [PubMed: 8630920]

34. Hemminki K, Forsti A, Fallah M, Sundquist J, Sundquist K, Ji J. Risk of cancer in patients with medically diagnosed hay fever or allergic rhinitis. Int J Cancer. 2014; 135:2397-403. [PubMed: 24692097]

35. Ober C, Yao TC. The genetics of asthma and allergic disease: a 21st century perspective. Immunol Rev. 2011; 242:10-30. [PubMed: 21682736]

36. Herrick CA, Bottomly K. To respond or not to respond: T cells in allergic asthma. Nat Rev Immunol. 2003; 3:405-12. [PubMed: 12766762]

37. Balkwill F, Charles KA, Mantovani A. Smoldering and polarized inflammation in the initiation and promotion of malignant disease. Cancer Cell. 2005; 7:211-7. [PubMed: 15766659]

38. Ulrik CS. Peripheral eosinophil counts as a marker of disease activity in intrinsic and extrinsic asthma. Clin Exp Allergy. 1995; 25:820-7. [PubMed: 8564720]

39. Tepper RI, Coffman RL, Leder P. An eosinophil-dependent mechanism for the antitumor effect of interleukin-4. Science. 1992; 257:548-51. [PubMed: 1636093]

40. Furbert-Harris P, Parish-Gause D, Laniyan I, Hunter KA, Okomo-Awich J, Vaughn TR, Forrest $\mathrm{KC}$, Howland C, Abdelnaby A, Oredipe OA. Inhibition of prostate cancer cell growth by activated eosinophils. Prostate. 2003; 57:165-75. [PubMed: 12949941]

41. Tato CM, O'Shea JJ. Immunology: what does it mean to be just 17? Nature. 2006; 441:166-8. [PubMed: 16688162]

42. Wilke CM, Kryczek I, Wei S, Zhao E, Wu K, Wang G, Zou W. Th17 cells in cancer: help or hindrance? Carcinogenesis. 2011; 32:643-9. [PubMed: 21304053]

43. Sfanos KS, Bruno TC, Maris CH, Xu L, Thoburn CJ, DeMarzo AM, Meeker AK, Isaacs WB, Drake CG. Phenotypic analysis of prostate-infiltrating lymphocytes reveals TH17 and Treg skewing. Clin Cancer Res. 2008; 14:3254-61. [PubMed: 18519750]

44. Hori S, Takahashi T, Sakaguchi S. Control of autoimmunity by naturally arising regulatory CD4+ T cells. Adv Immunol. 2003; 81:331-71. [PubMed: 14711059]

45. Hawrylowicz CM, O'Garra A. Potential role of interleukin-10-secreting regulatory T cells in allergy and asthma. Nat Rev Immunol. 2005; 5:271-83. [PubMed: 15775993]

46. Curiel TJ, Coukos G, Zou L, Alvarez X, Cheng P, Mottram P, Evdemon-Hogan M, Conejo-Garcia JR, Zhang L, Burow M, Zhu Y, Wei S, et al. Specific recruitment of regulatory T cells in ovarian carcinoma fosters immune privilege and predicts reduced survival. Nat Med. 2004; 10:942-9. [PubMed: 15322536]

47. Chen ML, Pittet MJ, Gorelik L, Flavell RA, Weissleder R, von Boehmer H, Khazaie K. Regulatory T cells suppress tumor-specific CD8 T cell cytotoxicity through TGF-beta signals in vivo. Proc Natl Acad Sci U S A. 2005; 102:419-24. [PubMed: 15623559]

48. Dunn GP, Old LJ, Schreiber RD. The three Es of cancer immunoediting. Annu Rev Immunol. 2004; 22:329-60. [PubMed: 15032581]

49. Barnes NC. The properties of inhaled corticosteroids: similarities and differences. Prim Care Respir J. 2007; 16:149-54. [PubMed: 17530144] 
Novelty and impact: Our study is novel in that we focused on lethal prostate cancer, which is the most clinically relevant prostate cancer phenotype. The impact of our study is that our finding - men with asthma have a lower risk of developing lethal prostate cancer - may lead to testable hypotheses about specific immune profiles in the etiology of lethal prostate cancer. 


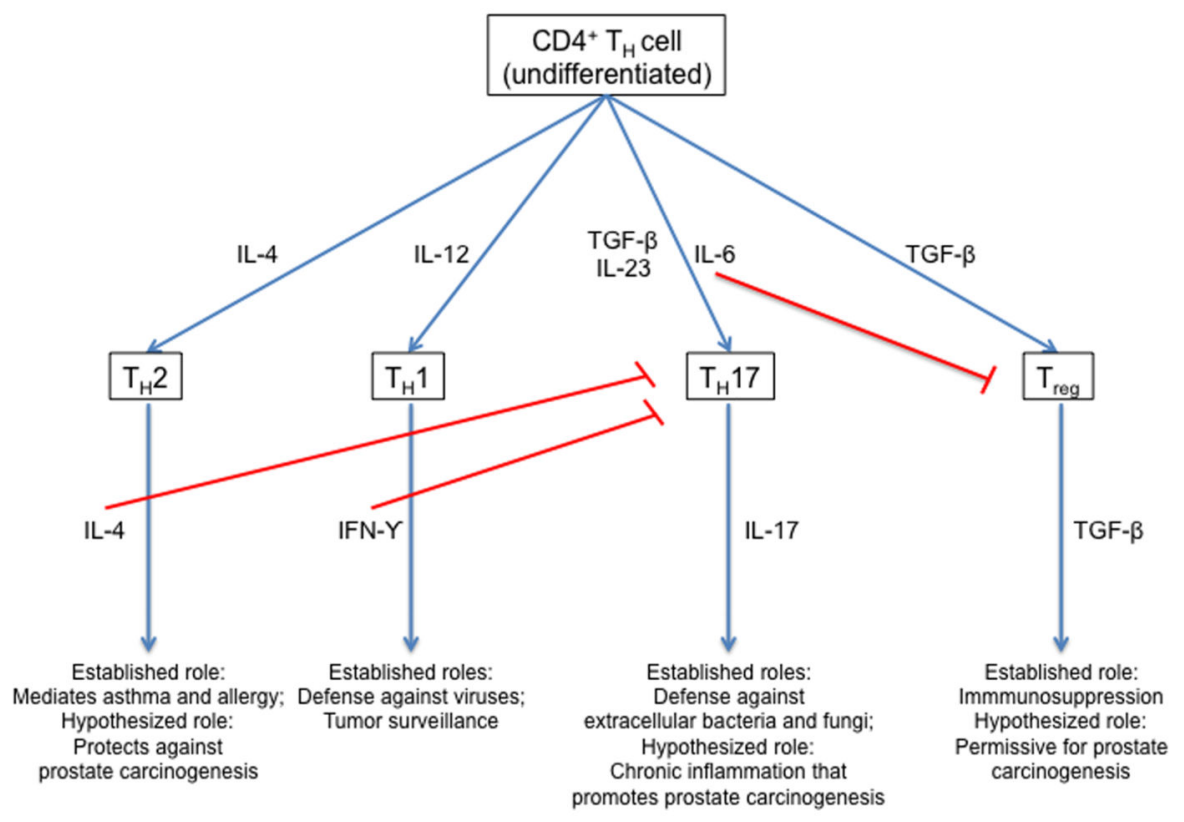

Figure 1.

CD4+ helper T cell differentiation paths, established roles for immune activity, and hypothesize roles in prostate carcinogenesis. Figure was modified from Tato and O'Shea. ${ }^{41}$ Modified and reprinted here by permission from Macmillan Publishers Ltd: Nature (Tato CM, O'Shea JJ. Immunology: what does it mean to be just 17? Nature 2006;441: 166-8), copyright (2006) 


\section{Table 1}

Selected characteristics by history of asthma and hayfever at baseline in $1986^{a}$, Health Professionals Followup Study

\begin{tabular}{|c|c|c|c|c|}
\hline \multirow[b]{2}{*}{ Characteristic } & \multicolumn{2}{|c|}{ Asthma } & \multicolumn{2}{|c|}{ Hayfever } \\
\hline & No & Yes & No & Yes \\
\hline Participants (n) & 45,364 & 2,516 & 35,766 & 12,114 \\
\hline Mean age (years) & $54.0 \pm 9.8$ & $53.0 \pm 9.5$ & $54.3 \pm 9.8$ & $52.9 \pm 9.4$ \\
\hline White $(\%)$ & 91 & 91 & 91 & 91 \\
\hline Mean BMI at age $21\left(\mathrm{~kg} / \mathrm{m}^{2}\right)$ & 23.0 & 22.9 & 23.0 & 22.9 \\
\hline Mean current BMI $\left(\mathrm{kg} / \mathrm{m}^{2}\right)$ & 25.0 & 24.7 & 25.0 & 24.8 \\
\hline Mean height (inches) & 70.1 & 70.1 & 70.2 & 70.1 \\
\hline Family history of prostate cancer (\%) & 12 & 12 & 12 & 13 \\
\hline History of hayfever (\%) & 23 & 73 & - & - \\
\hline History of asthma (\%) & - & - & 2 & 15 \\
\hline Diabetes mellitus (\%) & 3 & 3 & 3 & 3 \\
\hline Routine screening for PSA by $2002^{b}(\%)$ & 82 & 81 & 82 & 84 \\
\hline Current smoking (\%) & 10 & 8 & 10 & 8 \\
\hline $\begin{array}{l}\text { Vigorous physical activity }{ }^{c} \text { (MET- } \\
\text { hours/week) }\end{array}$ & 12.7 & 12.8 & 12.9 & 12.4 \\
\hline Regular aspirin use (\%) & 29 & 30 & 29 & 31 \\
\hline Regular use of oral steroid drugs ${ }^{d}(\%)$ & 1 & 5 & 1 & 1 \\
\hline Regular use of theophylline $^{d}(\%)$ & 1 & 17 & 1 & 4 \\
\hline \multicolumn{5}{|l|}{ Mean intakes } \\
\hline Energy (kcal/day) & 1984 & 2008 & 1978 & 2009 \\
\hline $\operatorname{Calcium}^{e}$ (mg/day) & 897 & 913 & 894 & 912 \\
\hline 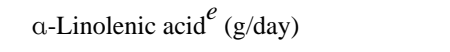 & 1.1 & 1.1 & 1.1 & 1.1 \\
\hline Bacon (servings/day) & 0.8 & 0.8 & 0.8 & 0.8 \\
\hline Fish (servings/day) & 0.4 & 0.4 & 0.4 & 0.4 \\
\hline Alcohol (g/day) & 11.3 & 11.2 & 11.4 & 11.1 \\
\hline Vitamin E from supplements (mg/day) & 40.4 & 43.6 & 39.5 & 43.8 \\
\hline
\end{tabular}

${ }^{a}$ All values (except age) are standardized to the age distribution of the study population.

${ }^{b}$ Among men who reported on $\geq 1$ follow-up questionnaire whether they had had a screening PSA test.

${ }^{c}$ METs=metabolic equivalents per week.

$d_{\text {Reported in } 1988 .}$

${ }^{e}$ Nutrients are adjusted for total energy intake by residual analysis. 


\section{Table 2}

Relative risk (RR) of total and lethal prostate cancer in relation to history of asthma and hayfever ${ }^{a}$ at baseline, Health Professionals Follow-up Study 1986-2012

\begin{tabular}{|c|c|c|c|c|}
\hline \multirow[t]{2}{*}{ Baseline history } & \multirow[t]{2}{*}{ Cases } & \multirow{2}{*}{$\begin{array}{c}\text { Person- } \\
\text { Years }\end{array}$} & \multicolumn{2}{|c|}{ RR $(95 \%$ CI $)$} \\
\hline & & & Age-adjusted & Multivariable-adjusted ${ }^{a}$ \\
\hline \multicolumn{5}{|c|}{ Total prostate cancer } \\
\hline No asthma & 6,014 & 942,751 & $1.00(\mathrm{ref})$ & $1.00(\mathrm{ref})$ \\
\hline Asthma & 280 & 52,425 & $0.89(0.79-1.00)$ & $0.89(0.78-1.00)$ \\
\hline No hayfever & 4,657 & 738,301 & 1.00 (ref) & 1.00 (ref) \\
\hline Hayfever & 1,637 & 256,875 & $1.07(1.01-1.13)$ & $1.07(1.01-1.13)$ \\
\hline \multicolumn{5}{|c|}{ Lethal prostate cancer } \\
\hline No asthma & 773 & 942,751 & $1.00(\mathrm{ref})$ & 1.00 (ref) \\
\hline Asthma & 25 & 52,425 & $0.67(0.45-1.00)$ & $0.67(0.45-1.00)$ \\
\hline No hayfever & 608 & 738,301 & $1.00(\mathrm{ref})$ & $1.00(\mathrm{ref})$ \\
\hline Hayfever & 190 & 256,875 & $1.06(0.90-1.24)$ & $1.06(0.90-1.25)$ \\
\hline
\end{tabular}

${ }^{a}$ Adjusted for age, diabetes mellitus, vigorous physical activity, current body mass index, body mass index at age 21 , height, family history of prostate cancer, race, pack-years smoked in the past 10 years. 


\section{Table 3}

Relative risk (RR) of total and lethal prostate cancer in relation to asthma and hayfever onset at baseline, Health Professionals Follow-up Study 1986-2012

\begin{tabular}{|c|c|c|c|}
\hline Baseline history & Cases $^{a}$ & Person-years & $\begin{array}{c}\text { Age-adjusted RR } \\
(95 \% \text { CI })\end{array}$ \\
\hline \multicolumn{4}{|l|}{ Total prostate cancer } \\
\hline No asthma & 6,014 & 942,751 & 1.00 (ref) \\
\hline \multicolumn{4}{|l|}{ Asthma } \\
\hline Recent past ( $<30$ years ago) & 73 & 15,238 & $0.82(0.65-1.03)$ \\
\hline Distant past ( 230 years ago) & 207 & 37,187 & $0.91(0.79-1.05)$ \\
\hline No hayfever & 4,657 & 738,301 & $1.00(\mathrm{ref})$ \\
\hline \multicolumn{4}{|l|}{ Hayfever } \\
\hline Recent past ( $<30$ years ago) & 547 & 153,525 & $1.01(0.93-1.11)$ \\
\hline Distant past ( 230 years ago) & 1,090 & 103,350 & $1.10(1.03-1.18)$ \\
\hline \multicolumn{4}{|l|}{ Lethal prostate cancer } \\
\hline No asthma & 773 & 942,751 & $1.00(\mathrm{ref})$ \\
\hline \multicolumn{4}{|l|}{ Asthma } \\
\hline Recent past ( $<30$ years ago) & 4 & 15,238 & $0.36(0.14-0.97)$ \\
\hline Distant past ( 230 years ago) & 21 & 37,187 & $0.81(0.52-1.24)$ \\
\hline No hayfever & 608 & 738,301 & 1.00 (ref) \\
\hline \multicolumn{4}{|l|}{ Hayfever } \\
\hline Recent past ( $<30$ years ago) & 52 & 153,525 & $0.95(0.71-1.26)$ \\
\hline Distant past ( $\geq 30$ years ago) & 138 & 103,350 & $1.10(0.92-1.33)$ \\
\hline
\end{tabular}

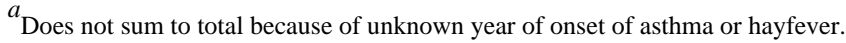




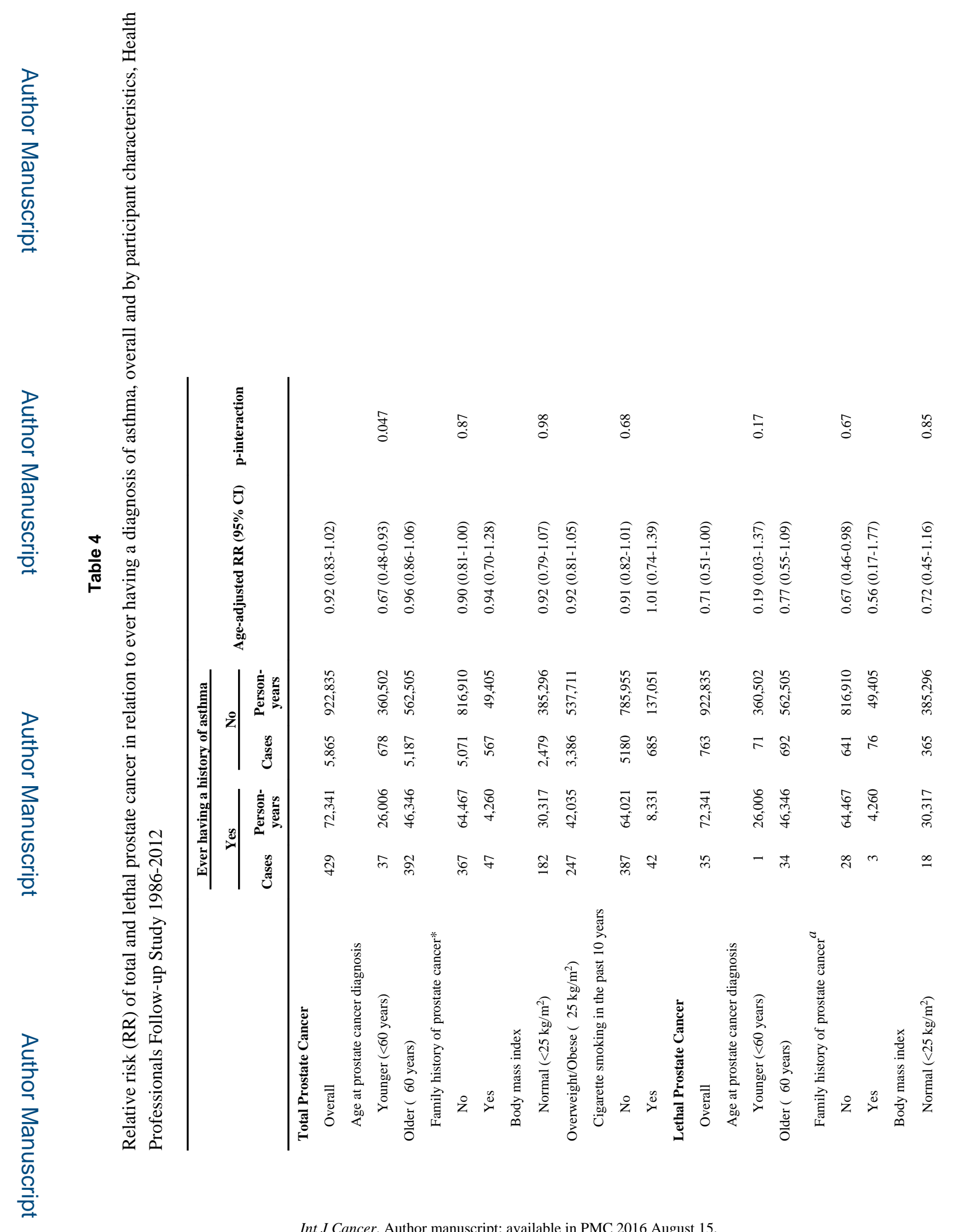




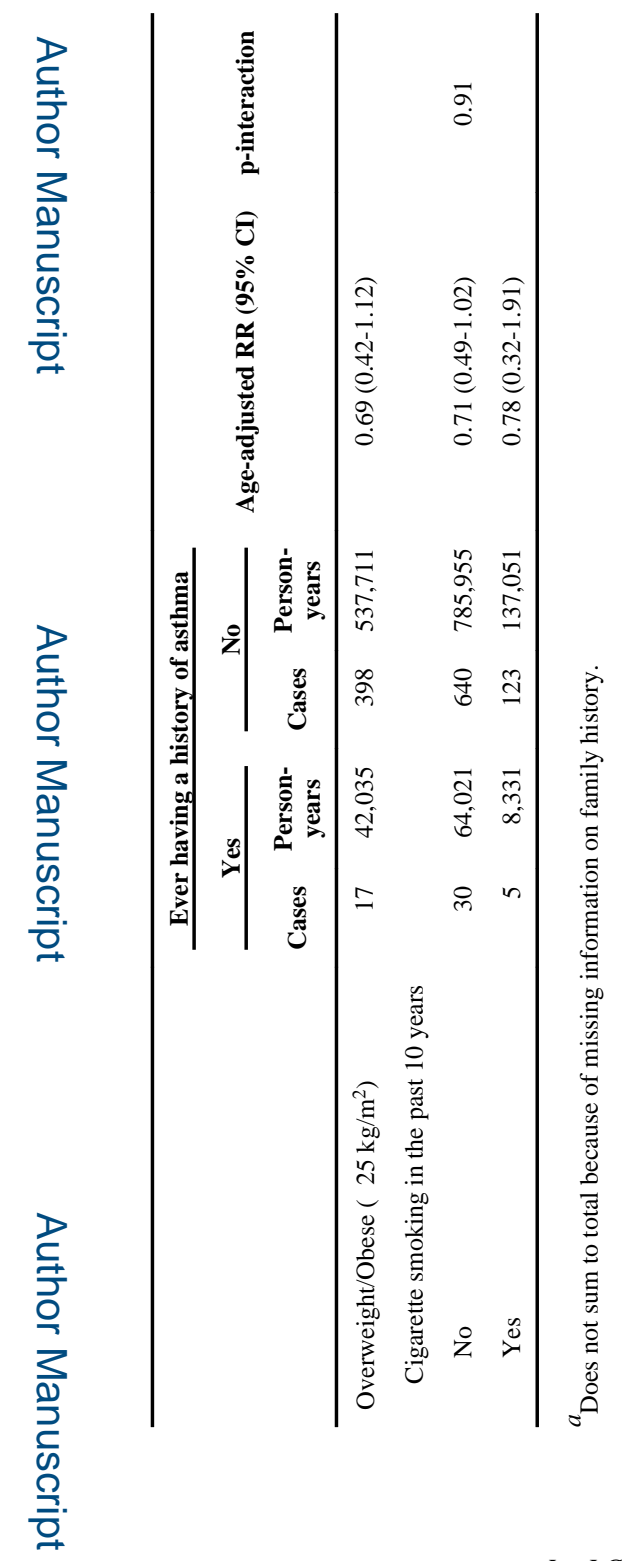

Int J Cancer. Author manuscript; available in PMC 2016 August 15. 


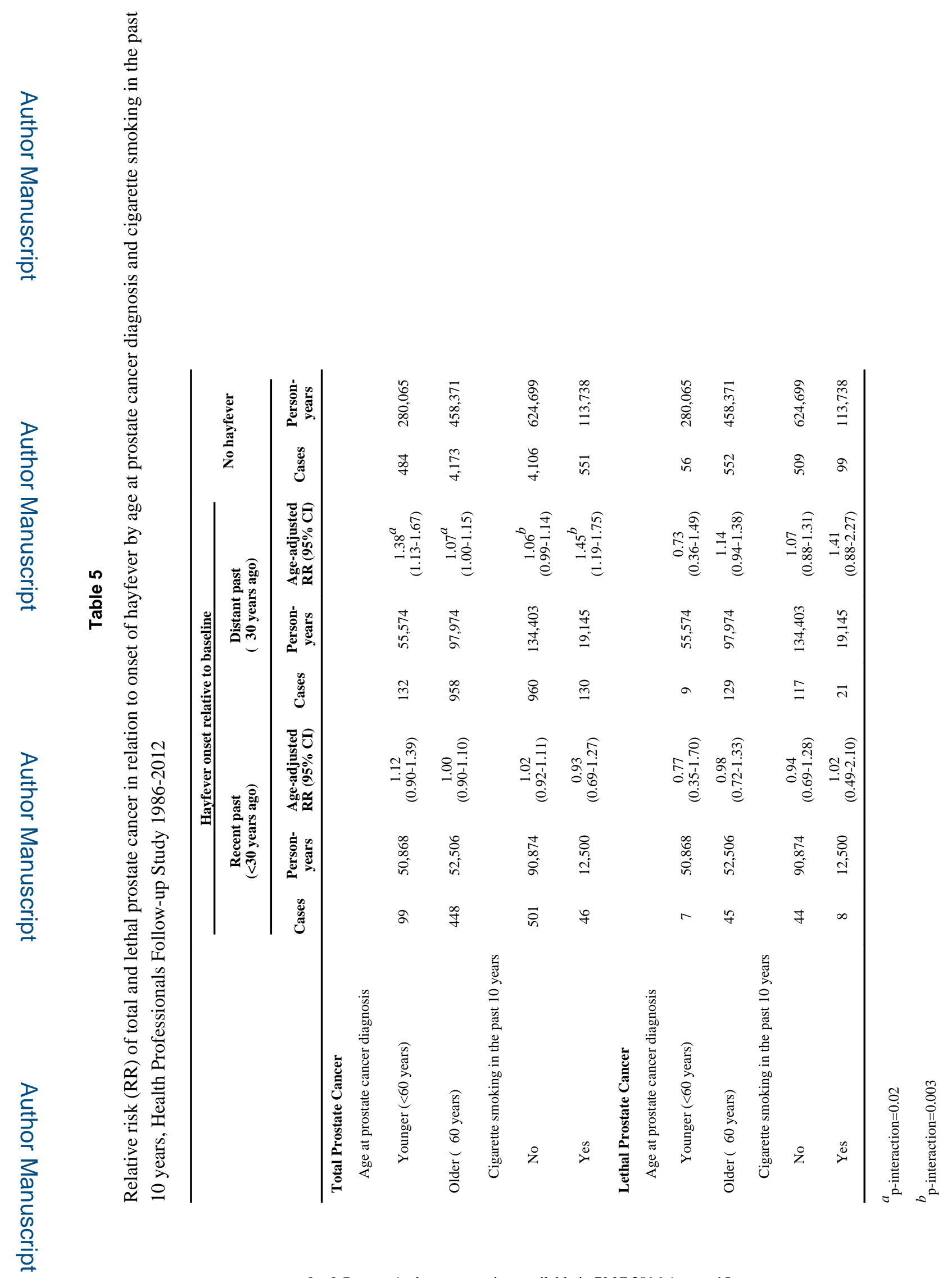

Int J Cancer. Author manuscript; available in PMC 2016 August 15. 